\title{
MicroRNA-138 promotes neuroblastoma SH-SY5Y cell apoptosis by directly targeting DEK in Alzheimer's disease cell model
}

Jin Miao ${ }^{1,2}$, Jin Jing $^{2}$, Yixiang Shao ${ }^{2^{*}}$ and Huaichang Sun ${ }^{1^{*}}$ (1)

\begin{abstract}
Background: Alzheimer's disease (AD) is a progressive neuro-degenerative disease with a major manifestation of dementia. MicroRNAs were reported to regulate the transcript expression in patients with Alzheimer's disease (AD). In this study, we investigated the roles of miR-138, a brain-enriched miRNA, in the AD cell model.

Methods: The targets of miRNA-138 was predicted by bioinformatic analysis. The expression levels of DEK at both mRNA and protein levels were determined by qRT-PCR and Western blot, respectively. Luciferase assays were carried out to examine cell viabilities. Hoechst 33258 staining was used to detect cell apoptosis.

Results: Our results demonstrated that the expression levels of miR-138 were increased in AD model, and DEK was a target of miR-138. Overexpression of miR-138 in SH-SY5Y cells obviously down-regulated the expression of DEK in SH-SY5Y cells, resulting in the inactivation of AKT and increased expression levels of proapoptotic caspase-3. MiR-138 mediated-suppression of DEK increased the susceptibility of cell apoptosis.
\end{abstract}

Conclusions: MicroRNA-138 promotes cell apoptosis of SH-SY5Y by targeting DEK in SH-SY5Y AD cell model. The regulation of miR-138 may contribute to $A D$ via down-regulation of the DEKJAKT pathway.

Keywords: miR-138, DEK, AKT, Apoptosis, Alzheimer's disease

\section{Background}

Alzheimer's disease (AD) is a progressive neuro-degenerative disease with a major manifestation of dementia [11]. There are a large number of Alzheimer's disease-related dementia patients all over the world, and they are usually accompanied by memory loss and behavioral changes, especially in older adults [26]. It has a complex progression involving neuronal dysplasia, angiogenic changes, and release of inflammatory mediators [33]. The early diagnosis of AD is complicated and laborious [13, 24]. Therefore, novel biomarkers and therapeutic agents have

\footnotetext{
*Correspondence: yxshao@ntu.edu.cn; sunh@yzu.edu.cn

${ }^{1}$ College of Veterinary Medicine, Yangzhou University, Yangzhou 225009 Jiangsu, People's Republic of China

${ }^{2}$ Laboratory Animal Center, Nantong University, Nantong 226000,

Jiangsu, People's Republic of China
}

been investigated for use in patient stratification. Noncoding RNAs have been demonstrated to be potential biomarkers and diagnostic tools for many diseases [21, 30].

Excessive apoptosis of cells might be the cause of neurodegenerative disease in $\mathrm{AD}$ patients. MicroRNAs (miRNAs) are small non-coding RNAs with molecular regulation functions in protein metabolism, cell apoptosis, and many other neurobiological processes [28]. Their functions in cell apoptosis show great potentials as regulating factors to alleviate cell death for $\mathrm{AD}$ patients. Previous studies have shown that the dysregulation of miRNA is in correlation with some types of neurodegenerative disease, and they are also involved in the regulation of some Alzheimer's disease-related proteins [16, 27]. Various miRNAs have been reported to be related 
with Alzheimer's disease, such as miR-29a/b-1 [9], miR107 [32], miR-34a [34], miR-122 [14], miR-455-3p [15, 17] and miR-26b [1]. It was reported that miR-26b was obviously up-regulated in Alzheimer's Disease, in which miR-26b participated in the activation of cycle entry, tau-phosphorylation, and postmitotic neuron apoptosis [1]. MiR-138, a key member of miRNAs, was reported to promote tau phosphorylation via the targeting of retinoic acid receptor alpha [35]. However, the regulation of miR138 in $\mathrm{AD}$ progression is still unknown. In the present study, we aimed to investigate the regulation of miR-138 in the clinical pathology of Alzheimer's disease.

DEK is a highly conserved ubiquitous oncogene in the proliferating cells of all tissues, which is regulated at both transcriptional and post-translational levels in DNA repair, replication, transcriptional regulation and mRNA splicing [19, 31]. Emerging evidence has suggested that the overexpression of DEK could inhibit cell death, and the silencing of DEK leads to cell apoptosis via stabilization and transcriptional activation of p53 [2, 38]. AKT, a serine/threonine kinase that has a wide range of substrates, is involved in the regulation of many biological processes, such as cell proliferation, cell growth and apoptosis $[12,23]$. The role of DEK and AKT in cellular survival suggests their functional mechanisms in Alzheimer's disease [20].

$\beta$-amyloid $(A \beta)$, a cleavage product of the amyloid precursor protein (APP), is the main component of insoluble senile plaques and its deposition is neurotoxic and can induce apoptosis of neurons [21]. In this study, we focused on exploring the inner associations of miR-138, DEK oncogene and AKT, and other factors that lead to apoptosis in AD cell model, which was established using A $\beta 1-42$ in SH-SY5Y cells.

\section{Materials and methods Antibodies and reagents}

Rabbit-anti-DEK antibody was obtained from Abcam, UK. Anti-Rabbit Cleaved Caspase-3 (Asp175) antibody, anti-Caspase-3 (8G10) antibody, anti-pAKT (ser473) antibody, anti-AKT antibody were obtained from CST, USA. HA-Tag (26D11) mouse antibody was obtained from AbMart. Mouse anti-GAPDH antibody was obtained from Sigma-Aldrich, USA. HRP-conjugated goat anti-mouse IgG and goat anti-rabbit IgG were obtained from Santa Cruz Biotechnology, USA. The ApopTag ${ }^{\circledR}$ kit were purchased from Millipore, USA. A $\beta 1$ 42 peptide (Sigma, USA) was dissolved in sterile distilled water at a concentration of $1 \mathrm{mM}$ and stored at $-20{ }^{\circ} \mathrm{C}$. Cells were transfected with equal amounts of miRNA$138 \mathrm{mimic}$ and/or miRNA-138 inhibitor for $48 \mathrm{~h}$, and then treated with $20 \mu \mathrm{M} \mathrm{A} \beta 42$ for $24 \mathrm{~h}$.

\section{Cell culture and transfection}

SH-SY5Y cell lines were cultured in DMEM with 10\% FBS and $100 \mathrm{U} / \mathrm{ml}$ penicillin/streptomycin (ATCC, USA) in a humidified environment at $37{ }^{\circ} \mathrm{C}$ with $5 \% \mathrm{CO}_{2}$. The cells were kept and seeded with a ratio of 1:5. The culture media was replaced every 4 days. The mature miR-138 sequences were obtained from the miRNA registry. The sequences of ASO miR-138 were designed, according to the principle of sequences complementary to the mature miR-138. Mature miR-138, ASO miR-138 and short-hairpin RNA directed against DEK (sense 5'-GGUGUGCAC UGUGAGAUCAtt- $3^{\prime}$, antisense 5'-UGAUCUCACAGU GCACACCct-3') were constructed using pcDNA3.1 plasmid as the backbone (GenePharma, China). Lipofectamine-3000 (Invitrogen) was used to transfect the cells (Invitrogen, USA).

\section{Luciferase assay}

The WT or MUT 3'-UTR luciferase reporter plasmids, as well as a miR-138 mimic or miR-138 inhibitor, were co-transfected to SH-SY5Y cells. Cells were harvested at $48 \mathrm{~h}$ after transfection and the Dual-Luciferase Reporter Assay (Promega, WI, USA) was performed.

\section{RNA isolation and quantitative RT-PCR}

Total RNAs were extracted using TRIZOL (Invitrogen, USA). For miRNA analysis, the TaqMan microRNA Reverse Transcription reagents and the Universal PCR Master Mix with microRNA real-time PCR primers (Applied Biosystems) were used. Total RNAs $(1 \mu \mathrm{g})$ were reverse transcribed to cDNAs. For mRNA expression analysis, $1 \mu \mathrm{g}$ of total RNAs were reverse-transcribed with the TaqMan Reverse Transcription Reagents (Applied Biosystems N808-0234). Gene expression was measured by SYBR green (Applied Biosystems, USA). U6 and GAPDH were used as endogenous control. The primers used were listed in Table 1.

\section{Western blot}

Cells were washed and lysed in buffer $(50 \mathrm{mM}$ Tris- $\mathrm{HCl}$ $\mathrm{pH}$ 8.0, $150 \mathrm{mM} \mathrm{NaCl}, 1 \% \mathrm{NP}-40,0.5 \%$ sodium deoxycholate, $0.1 \%$ SDS) with protease inhibitor cocktail (Roche, Switzerland) and $1 \mathrm{mM}$ phenylmethylsulfonyl-fluoride

Table 1 Sequences of primers used in qRT-PCR

\begin{tabular}{lll}
\hline Name & Forward primer $\left(\mathbf{5}^{\prime} \mathbf{-} \mathbf{3}^{\prime}\right)$ & Reversed primer $\left(\mathbf{5}^{\prime} \mathbf{-} \mathbf{3}^{\prime} \mathbf{)}\right.$ \\
\hline miR-138 & AGCUGGUGUUGUGAAUC & GTGCAGGGTCCGAGGT \\
U6 & GTAGTCGGCGAAGGTCTCAC & ACCGTGGATGCAATGCCTAA \\
DEK & AAAGCCACCTACAGATGA & TCCTCTCAGTCAAATCACAAGC \\
GAPDH & GGATG & \\
\hline
\end{tabular}


for $30 \mathrm{~min}$. Extracts were centrifuged at $14,000 \times g$ for $30 \mathrm{~min}$ and concentrations were measured using a BCA Protein Quantitative Analysis Kit (Biocolors, Shanghai, China). A total of $20 \mathrm{mg}$ lysates was boiled, separated by SDS-PAGE and transferred to PVDF membranes. The membranes were blocked using 5\% skim milk for $1 \mathrm{~h}$ and then incubated at $4{ }^{\circ} \mathrm{C}$ for overnight with anti-DEK (1:1000), anti-AKT (1:1000), anti-p-AKT (1:1000), antiCleaved Caspase-3 (1:1000), and anti-Caspase-3 (1:1000). After washing, membranes were incubated with HRPconjugated goat anti-mouse antibody $(1: 5000)$ at $25^{\circ} \mathrm{C}$ for $2 \mathrm{~h}$. Western blot was carried out by Immobilon Western Chemiluminescent HRP Substrate (Millipore, USA) and quantified by Image J. All experiments were conducted for three times.

\section{Flow cytometry}

Cells were centrifuged and stained with Annexin V-FITC and propidium iodide (PI) using the Annexin V-FITC Apoptosis Detection Kit (BD Biosciences). Briefly, cells were re-suspended and $5 \mu \mathrm{l}$ of Annexin V-FITC and $1 \mu \mathrm{l}$ PI were added. Flow cytometry was conducted on a flow cytometer (Becton-Dickinson; LSR II) and apoptotic cell percentage was determined.

\section{Hoechst 33258 staining}

Cell apoptosis was evaluated by Hoechst 33258 staining. After treatment, cells were harvested, washed, and fixed with $4 \%(\mathrm{v} / \mathrm{v})$ paraformaldehyde at $25^{\circ} \mathrm{C}$ for $30 \mathrm{~min}$. Cells were washed, stained with $2 \mu \mathrm{l} 5 \mathrm{mg} / \mathrm{ml}$ Hoechst 33258 and incubated for $10 \mathrm{~min}$. Stained cells were washed and observed under a fluorescence microscope (Leica DMI4000B, Germany). Cell apoptosis was calculated by DNA fragmentation and nuclear shrinkage. The apoptotic rate was calculated as several apoptotic cells/number of total cells $(>300) \times 100$.

\section{Co-immunoprecipitation (Co-IP)}

Plasmids were transfected into SH-SY5Y cells using Lipofectamine 3000. Cell lysate was harvested at $48 \mathrm{~h}$ after transfection in non-denaturing lysis buffer containing $20 \mathrm{mM}$ Tris $\mathrm{HCl}$ (pH 8.0), $137 \mathrm{mM} \mathrm{NaCl}, 10 \%$ glycerol, $1 \%$ Nonidet P-40, 2 mM EDTA and protease inhibitors. The supernatant was incubated with the primary antibody (1:500) and $A+G$ Sepharose at $4{ }^{\circ} \mathrm{C}$ for $4 \mathrm{~h}$. The beads were washed and reactivated by boiling in sample buffer. The samples were detected by Western blot.

\section{Statistical analysis}

SPSS 19.0 was used for data analysis. Data were expressed as mean \pm stand deviation (SD). T-test was used for comparisons between two groups. One-way ANOVA and Bonferroni's post hoc test was used for exploring the differences among multi-groups. $P<0.05$ was considered as statistically significant.

\section{Results}

The expression levels of miR-138 were increased in AD model

qRT-PCR was carried to measure the expression levels of miR-138 in AD model. The expression of miR-138 was obviously upregulated in A $\beta$ treated SH-SY5Y cells than that in the untreated (Control) group $(P<0.01)$ (Fig. 1). Therefore, it was confirmed that the expression of miR-138 was significantly upregulated in AD model.

\section{DEK was a target of miR-138}

Firstly, we identified the successful transfection of miR138 by RT-PCR. The relative expression of miR-138 was remarkably elevated after transfection with miR-138 mimic $(P<0.01)$ and decreased after transfection with miR-138 inhibitor $(P<0.01)$ (Fig. 2a). The relationship between DEK and miR-138 was then evaluated by bioinformatics analysis and luciferase assay. DEK was predicted to be a target of miR-138 through bioinformatics analysis using TargetScan. org and microRNA. org (Fig. 2b). Luciferase reporter assay results demonstrated that the activity was greatly reduced after transfection with miR-138 and DEK $3^{\prime}$-UTR, but obviously elevated by miR-138 inhibitor and DEK $3^{\prime}$-UTR $(P<0.01)$ (Fig. 2c, d). In addition, the expression levels of DEK were significantly decreased by miRNA-138 mimic at both mRNA (Fig. 2e) and protein (Fig. 2f, g) levels, but was notably enhanced by miR-138 inhibitor $(P<0.01)$ (Fig. $2 \mathrm{e}-\mathrm{g})$. These data indicated that DEK was targeted by miR-138.

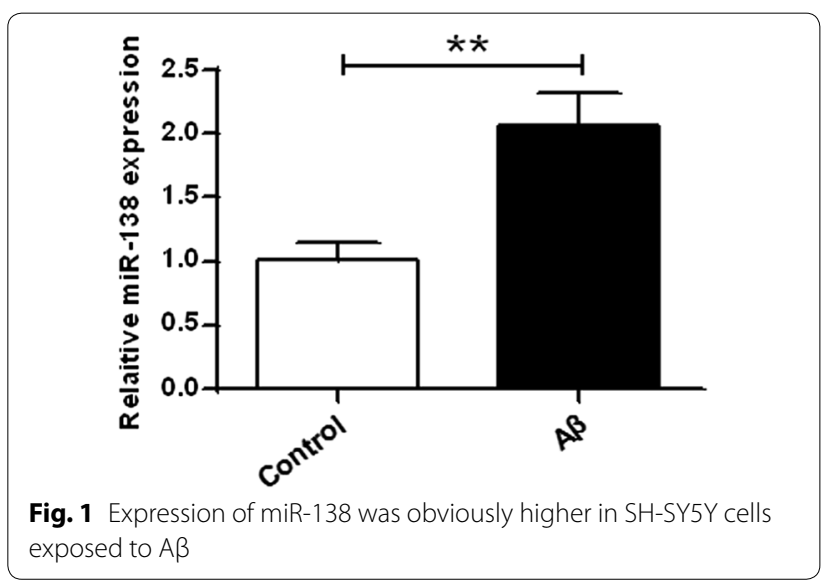




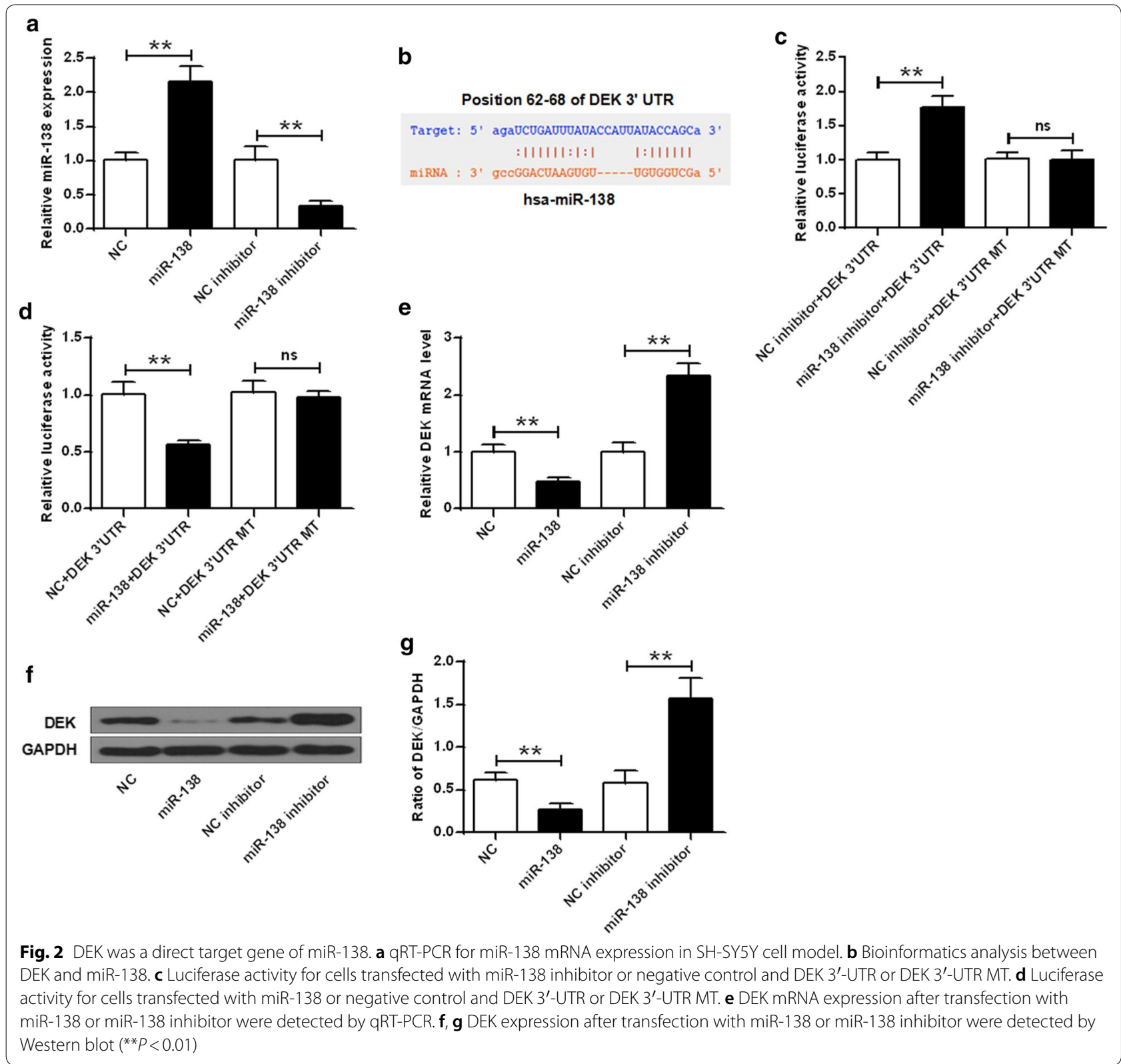

DEK activated AKT phosphorylation (Ser473) while inhibited cleaved caspase-3 expression in SH-SY5Y cells

The role of DEK in AKT activation was investigated by western blot. DEK inhibited caspase- 3 activity via activating the $\mathrm{AKT}$ signaling pathway in $\mathrm{A} \beta$ treated cells $(P<0.05, P<0.01)$ (Fig. 3a, b). Silencing of DEK suppressed AKT phosphorylation and induced a change in cleaved caspase- 3 activity $(P<0.05, P<0.01)$ (Fig. $3 c, d)$. Immunoprecipitated complexes were analyzed by Western blot for AKT and hemagglutinin (HA)-tagged DEK (Fig. 3e). The results suggested that the two molecules could interact with each other. These results demonstrated that DEK inhibited the expression of cleaved caspase- 3 through the activation of the AKT signaling.

\section{MiR-138 mediated suppression of DEK increased susceptibility of cell apoptosis}

Western blot was utilized to examine the effect of miR-138 in caspase-3 activity. Our results showed that miRNA-138 changed caspase-3 activity that was affected by $\mathrm{A} \beta$ treatment $(P<0.01)$ (Fig. $4 \mathrm{a}, \mathrm{b})$. The flow cytometry indicated that the cellular apoptosis was $35.42 \%, 51.40 \%$ and $38.26 \%$ with $\mathrm{A} \beta$ alone, $\mathrm{A} \beta$ plus 


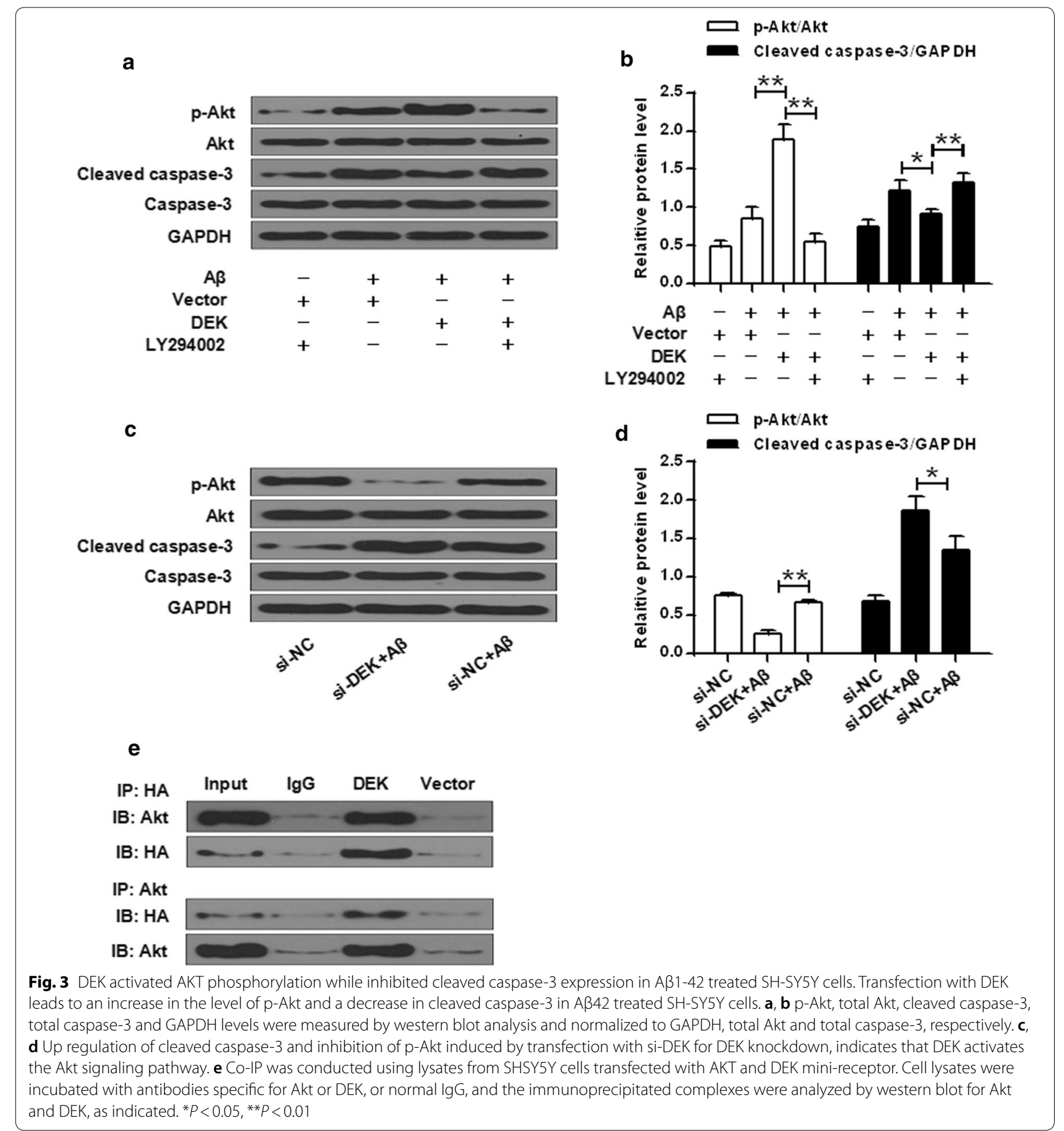

miRNA-138 mimic and A $\beta$ plus miRNA-138 inhibitor, respectively $(P<0.05)$ (Fig. $4 \mathrm{c}, \mathrm{d})$. Additionally, apoptotic cells in the miRNA-138 group were significantly higher than that in the negative control $(P<0.05)$ (Fig. 4e, f). These results indicated that miRNA-138 induced increased cell apoptosis in SH-SY5Y cells exposed to $A \beta$.

\section{Discussion}

Dementia, a commonly known symptom of Alzheimer's disease, results in disorientation, loss of memory, and visual-spatial abilities in elderly people [3]. Neuro-pathology in the brains exists in $\mathrm{AD}$ patients for years before these symptoms [10]. Therefore, it is critical to develop novel and practical biomarkers for early diagnosis of 


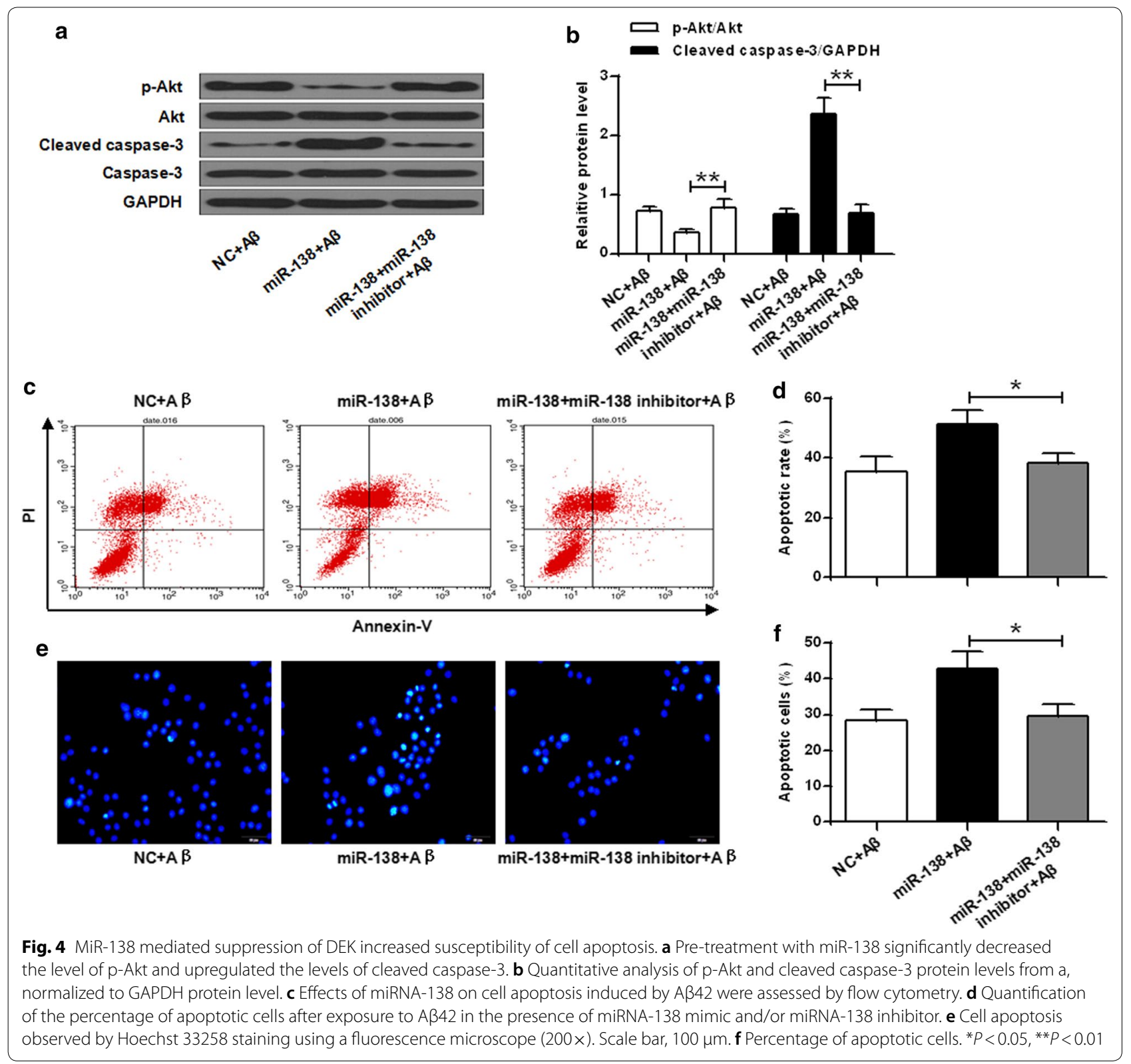

AD. Non-coding RNAs arise as new therapeutic agents for various human diseases, including neuro-defective diseases [30], cardiovascular diseases [18], and human cancers [7]. In this study, we investigated the role of miRNA-138 and its associations with oncogene DEK and AKT in the regulation of neuron apoptosis.

MiRNAs are small noncoding RNAs that can regulate gene expression at the post-transcriptional level via binding to $3^{\prime}$-UTR of the target gene [4]. Previous reports have identified several miRNAs that explicitly expressed in the brain cells, and some are involved in neuron differentiation, synaptic plasticity, and memory formation [20]. Several miRNAs have been reported to be related with Alzheimer's disease, such as miR29a/b-1 [9], miR-107 [32], miR-34a [34], miR-122 [14], miR-455-3p [15, 17], and miR-26b [1]. For example, it was noted that microRNA could regulate Alzheimer's amyloid precursor protein expression [8]. Dysregulation of specific miRNAs was observed in Alzheimer's disease [32]. The qRT-PCR results in this study revealed that the expression of miR-138 were remarkably upregulated in A $\beta$ treated SH-SY5Y cells compared to that in the untreated cells. Our findings that the expression of miR-138 was elevated in AD cell model 
are in consistence with previous researches, indicating that miR-138 actually plays a regulatory role in AD progression.

The human DEK oncogene was first discovered as a fusion with the gene encoding the CAN nucleoporin protein in myeloid leukemia patients [6]. Up-regulated expression of DEK was related to many human diseases, such as uterine cervical cancer [36], gastric cancer [25], and neuroblastoma tumor [39]. Over-expression of DEK could inhibit cell death, and knockdown of DEK could result in cell apoptosis. It was reported that DEK was a target of miR-200a [37]. The bioinformatics analysis illustrates that DEK was a target of miR-138. The luciferase reporter assay demonstrates that the transcriptional activity in cells was substantially decreased after transfection with miR-138 and DEK $3^{\prime}$-UTR, but remarkably elevated by miR-138 inhibitor and DEK $3^{\prime}$-UTR. In addition, the mRNA and protein levels of DEK were greatly decreased by miRNA-138 mimic but was notably enhanced by miR-138 inhibitor. Our results further confirmed that DEK was a direct target gene of miR-138.

It was demonstrated that DEK markedly attenuated AKT phosphorylation [5]. Our qRT-PCR and western blot results revealed that DEK could inhibit caspase-3 activity via the AKT signaling pathway. In addition, silencing of DEK suppressed AKT phosphorylation and affected caspase-3 activity. The results of Co-IP for SHSY5Y cells transfected with AKT and DEK mini-receptor also suggested that DEK inhibited the expression of cleaved caspase- 3 through activation of AKT.

AKT signaling pathways play essential roles in the regulation of various cell functions such as nutrient metabolism, cell growth, apoptosis and survival [29]. The activation of the AKT pathway was reported to be involved with miRNA interactions [22]. In our experiments, miR-138 significantly decreased p-AKT and upregulated the expression of cleaved caspase- 3 protein.

\section{Conclusion}

The results of flow cytometry and apoptotic test demonstrated that apoptotic cells in the miR-138 mimic group were much higher than that in the control. It indicated that miRNA-138 induced increased cell apoptosis in this AD cell model. Our observations further confirmed that the regulation of microRNA-138 may contribute to $A D$ through down-regulation of DEK/AKT pathway.

\section{Abbreviations}

AD: Alzheimer's disease; miRNAs: MicroRNAs.

Acknowledgements

Not applicable.
Authors' contributions

HCS supervised the whole study, analyzed the data, prepared the manuscript. $J M, J J, Y X S$ collected and analyzed the data, prepared the manuscript. All authors read and approved the final manuscript.

\section{Funding}

Not applicable.

\section{Availability of data and materials}

The analyzed data sets generated during the study are available from the corresponding author on reasonable request.

\section{Ethics approval and consent to participate}

The present study was approved by the Ethics Committee of College of Veterinary Medicine, Yangzhou University.

\section{Consent for publication}

Not applicable.

\section{Competing interests}

The authors declare that they have no competing interests.

Received: 23 September 2019 Accepted: 21 June 2020

Published online: 31 July 2020

\section{References}

1. Absalon S, Dawn MK, Venkatesan R, Anna MK. MiR-26b, upregulated in Alzheimer's disease, activates cell cycle entry, tau-phosphorylation, and apoptosis in postmitotic neurons. J Neurosci. 2013;33:14645-59.

2. Ageberg M, Gullberg U, Lindmark A. The involvement of cellular proliferation status in the expression of the human proto-oncogene DEK Haematologica. 2006;91:268-9.

3. Association, Alzheimer's. 2018 Alzheimer's disease facts and figures. Alzheimer's \& Dementia. 2018;14:367-429.

4. Croce CM, Calin GA. miRNAs, cancer, and stem cell division. Cell. 2005;122:6-7.

5. Cui Y, Park JY, Wu J, Lee JH, Yang YS, Kang MS, Jung SC, Park JM, Yoo ES, Kim SH. 'Dieckol attenuates microglia-mediated neuronal cell death via ERK, Akt and NADPH oxidase-mediated pathways. Korean J Physiol Pharmacol. 2015:19:219-28.

6. Fomerod M, Morreaul H. Interaction of cellular proteins with the leukemia specific fusion proteins DEK-CAN and SET-CAN and their normal counterpart, the nucleoporin CAN. CAN Protein Mediat Nucleocytoplasm Transp Oncogen Prop. 1996;12:59.

7. Gupta RA, Shah N, Wang KC, Kim J, Horlings HM, Wong DJ, Tsai MC, Hung T, Argani P, Rinn JL. Long non-coding RNA HOTAIR reprograms chromatin state to promote cancer metastasis. Nature. 2010;464:1071.

8. Hébert SS, Horré K, Nicolaï L, Bergmans B, Papadopoulou AS, Delacourte A, De Strooper B. MicroRNA regulation of Alzheimer's Amyloid precursor protein expression. Neurobiol Dis. 2009;33:422-8.

9. Hébert SS, Horré K, Nicolaï L, Papadopoulou AS, Mandemakers W, Silahtaroglu AN, Kauppinen S, Delacourte A, De Strooper B. Loss of microRNA cluster miR-29a/b-1 in sporadic Alzheimer's disease correlates with increased BACE1/ $\beta$-secretase expression. Proc Natl Acad Sci. 2008;105:6415-20

10. Hellmuth J, Milanini B, Masliah E, Tartaglia MC, Dunlop MB, Moore DJ, Javandel S, DeVaughn S, Valcour V. A neuropathologic diagnosis of Alzheimer's disease in an older adult with HIV-associated neurocognitive disorder. Neurocase. 2018:24:213-9.

11. Heneka MT, Carson MJ, El Khoury J, Landreth GE, Brosseron F, Feinstein DL, Jacobs AH, Wyss-Coray T, Vitorica J, Ransohoff RM. Neuroinflammation in Alzheimer's disease. Lancet Neurol. 2015;14:388-405.

12. Jiang ZY, Zhou QL, Coleman KA, Chouinard M, Boese Q, Czech MP. Insulin signaling through $\mathrm{Akt} /$ protein kinase $B$ analyzed by small interfering RNA-mediated gene silencing. Proc Natl Acad Sci. 2003;100:7569-74.

13. Khachaturian ZS. Diagnosis of Alzheimer's disease. Arch Neurol. 1985;42:1097-105.

14. Kumar S, Chawla YK, Ghosh S, Chakraborti A. Severity of hepatitis $C$ virus (genotype-3) infection positively correlates with 
circulating microRNA-122 in patients sera. Dis Markers. 2014. https://doi. org/10.1155/2014/435476.

15. Kumar S, Reddy AP, Yin X, Reddy PH. Novel MicroRNA-455-3p and its protective effects against abnormal APP processing and amyloid beta toxicity in Alzheimer's disease. Biochim et Biophys Acta BBA Mol Basis Dis. 2019. https://doi.org/10.1016/j.bbadis.2019.06.006.

16. Kumar S, Reddy PH. Are circulating microRNAs peripheral biomarkers for Alzheimer's disease? Biochim et Biophys Acta BBA Mol Basis Dis. 2016;1862:1617-27.

17. Kumar S, Reddy PH. MicroRNA-455-3p as a potential biomarker for Alzheimer's disease: an update. Front Aging Neurosci. 2018;10:41.

18. Kumarswamy R, Thum T. Non-coding RNAs in cardiac remodeling and heart failure. Circ Res. 2013;113:676-89.

19. Liu K, Feng T, Liu J, Zhong M, Zhang S. Silencing of the DEK gene induces apoptosis and senescence in CaSki cervical carcinoma cells via the upregulation of NF-kB p65. Biosci Rep. 2012;32:323-32.

20. Makeyev EV, Zhang J, Carrasco MA, Maniatis T. The MicroRNA miR-124 promotes neuronal differentiation by triggering brain-specific alternative pre-mRNA splicing. Mol Cell. 2007;27:435-48.

21. Mehler MF, Mattick JS. Non-coding RNAs in the nervous system. J Physiol. 2006;575:333-41.

22. Mellios N, FeldmanDA Sheridan SD, Ip JPK, Kwok S, Amoah SK, Rosen B, Rodriguez BA, Crawford B, Swaminathan R. MeCP2-regulated miRNAs control early human neurogenesis through differential effects on ERK and AKT signaling. Mol Psychiatry. 2018;23:1051.

23. Miao W, Luo Z, Kitsis RN, Walsh K. Intracoronary, adenovirus-mediated Akt gene transfer in heart limits infarct size following ischemia-reperfusion injury in vivo. J Mol Cell Cardiol. 2000;32:2397-402.

24. Mueller SG, Weiner MW, Thal LJ, Petersen RC, Jack CR, Jagust W, Trojanowski JQ, Toga AW, Beckett L. Ways toward an early diagnosis in Alzheimer's disease: the Alzheimer's Disease Neuroimaging Initiative (ADNI). Alzheimer's Dementia. 2005;1:55-66.

25. Piao J, Shang Y, Liu S, Piao Y, Cui X, Li Y, Lin Z. High expression of DEK predicts poor prognosis of gastric adenocarcinoma. Diagn Pathol. 2014;9:67.

26. Risacher SL, Kim S, Nho K, Foroud T, Shen L, Petersen RC, Jack CR Jr, Beckett LA, Aisen PS, Koeppe RA. APOE effect on Alzheimer's disease biomarkers in older adults with significant memory concern. Alzheimer's Dementia. 2015;11:1417-29.

27. Sarkar SN, Russell AE, Engler-Chiurazzi EB, Porter KN, Simpkins JW. MicroRNAs and the genetic nexus of brain aging, neuroinflammation, neurodegeneration, and brain trauma. Aging Dis. 2019;10:329.
28. Seitz H. On the number of functional microRNA targets. Mol Biol Evol. 2019;36:1596-7.

29. Song G, Ouyang G, Bao S. The activation of Akt/PKB signaling pathway and cell survival. J Cell Mol Med. 2005;9:59-71.

30. Tan L, Yu JT, Hu N, Tan L. Non-coding RNAs in Alzheimer's disease. Mol Neurobiol. 2013;47:382-93.

31. Waldmann T, Scholten I, Kappes F, Hu HG, Knippers R. The DEK proteinan abundant and ubiquitous constituent of mammalian chromatin. Gene. 2004;343:1-9.

32. Wang WX, Rajeev BW, Stromberg AJ, Ren N, Tang G, Huang Q, Rigoutsos I, Nelson PT. The expression of microRNA miR-107 decreases early in Alzheimer's disease and may accelerate disease progression through regulation of $\beta$-site amyloid precursor protein-cleaving enzyme 1. J Neurosci. 2008;28:1213-23.

33. Wang WY, Tan MS, Yu JT, Tan L. Role of pro-inflammatory cytokines released from microglia in Alzheimer's disease. Ann Transl Med. 2015;3:136.

34. Wang X, Liu P, Zhu H, Xu Y, Ma C, Dai X, Huang L, Liu Y, Zhang L, Qin C. miR-34a, a microRNA up-regulated in a double transgenic mouse model of Alzheimer's disease, inhibits bcl2 translation. Brain Res Bull. 2009;80:268-73.

35. Wang X, Tan L, Lu Y, Peng J, Zhu Y, Zhang Y, Sun Z. MicroRNA-138 promotes tau phosphorylation by targeting retinoic acid receptor alpha. FEBS Lett. 2015;589:726-9.

36. Wu Q, Li Z, Lin H, Han L, Liu S, Lin Z. DEK overexpression in uterine cervical cancers. Pathol Int. 2008;58:378-82.

37. Wu X, Wu G, Wu Z, Yao X, Li G. MiR-200a suppresses the proliferation and metastasis in pancreatic ductal adenocarcinoma through downregulation of DEK gene. Transl Oncol. 2016;9:25-31.

38. Yi HC, Liu YL, You P, Pan JS, Zhou JY, Liu ZJ, Zhang ZY. Overexpression of DEK gene is correlated with poor prognosis in hepatocellular carcinoma. Mol Med Rep. 2015;11:1318-23.

39. Zheng J, Kohler ME, Chen Q, Weber J, Khan J, Johnson BD, Orentas RJ. Serum from mice immunized in the context of Treg inhibition identifies DEK as a neuroblastoma tumor antigen. BMC Immunol. 2007:8:4.

\section{Publisher's Note}

Springer Nature remains neutral with regard to jurisdictional claims in published maps and institutional affiliations.
Ready to submit your research? Choose BMC and benefit from:

- fast, convenient online submission

- thorough peer review by experienced researchers in your field

- rapid publication on acceptance

- support for research data, including large and complex data types

- gold Open Access which fosters wider collaboration and increased citations

- maximum visibility for your research: over 100M website views per year

At BMC, research is always in progress.

Learn more biomedcentral.com/submissions 